\title{
Digital Implementation of the 2-compartmental Pinsky-Rinzel Pyramidal Neuron Model
}

\author{
E. Rahimian, S. Zabihi, M. Amiri, and B. Linares-Barranco
}

\begin{abstract}
It is believed that brain-like computing system can be achieved by the fusion of electronics and neuroscience. In this way, the optimized digital hardware implementation of neurons, primary units of nervous system, play a vital role in neuromorphic applications. Moreover, one of the main features of pyramidal neurons in cortical areas is bursting activities which has a critical role in synaptic plasticity. The Pinsky-Rinzel model is a nonlinear 2-compartmental model for $\mathrm{CA} 3$ pyramidal cell which widely used in neuroscience. In this paper, a modified Pinsky-Rinzel pyramidal neuron model is proposed by replacing its complex differential equations with piecewise linear approximation. Next, a digital circuit is designed for the simplified model to be able to implement on a low-cost digital hardware, such as fieldprogrammable gate array (FPGA). Both original and proposed models are simulated in MATLAB and next digital circuit simulated in VIVADO are also compared to show that obtained results are in good agreement. The presented circuit advances preceding designs with regards to the ability to replicate essential characteristics of different firing activities including bursting and spiking in the compartmental model. This new circuit has various applications in neuromorphic engineering such as developing new neuro-inspired chips.
\end{abstract}

Index Terms - Digital implementation, Pinsky-Rinzel Model, bursting pattern, pyramidal neuron, piecewise-linear approximation, brain.

\section{INTRODUCTION}

$\mathrm{T}$ HE brain consists of a great number of building blocks which is called neuronal cells and they are synaptically interconnected [1]-[3]. Recent studies in computational neuroscience and computational intelligence have shown a strong tendency towards a better understanding of the principles of brain information processing and the details of neuronal signal transmission [4]. Such research is motivated by the desire to obtain a more comprehensive picture of brain capabilities in information processing and at the same time to investigate how this understanding could be used to improve traditional information processing systems. This supports to build and extend the advanced neuromorphic processing systems. In recent years, inspiring from brain, researchers have proposed digital and analog electronic systems [5]-[8], such as a digital

E. Rahimian is with the Department of electronics, Amirkabir University of Technology, Tehran, Iran (e-mail: e.rahimian@aut.ac.ir).

S. Zabihi is with the Department of electronics, Amirkabir University of Technology, Tehran, Iran (soheil_zabihi@aut.ac.ir). architecture having self-repairing mechanism to increase the system [9]-[14]. Moreover, several digital circuits focused on neuron-astrocyte interactions and synaptic plasticity are also developed by other researchers [3], [8], [15]-[17].

Understanding the behavior of primary building blocks of nervous system, neurons, plays a vital role in neuromorphic fields [4]. The recurrent connectivity within the CA3 network of the hippocampus, supports a strong computational capacity which can mediate behavioral processes including pattern completion [18], [19]. At the cellular level, CA3 pyramidal neurons show various firing patterns, ranging from single action potentials to complex bursts. There are several models describe neuron dynamics using nonlinear differential equations [6]. Traub proposed a 19-compartment model of a CA1 pyramidal neuron to simulate fundamental features of a CA1 neuron [20]. However, a more simplified model is required to reduce the computational demand in order to extend the model and create a network to investigate the effects of key parameters on network dynamics. By reducing a complex 19-compartment cable model [20], Pinsky and Rinzel suggested a new compartmental neuron model [21]. Next, using Pinsky-Rinzel model, Kepecs and Wang proposed a two-compartment model for producing bursting and spiking dynamics [22]. In the latter, soma and axon are modeled in one compartment and only necessary ionic currents for producing spikes has been considered. The second compartment which is dendrite, includes a persistent sodium and a slowly activating potassium currents. These two currents are able to generate bursting dynamics [22], [23].

Firing activity of neurons play a significant role in various applications such as processing information in the brain. Understanding neural computation needs knowledge about how neurons switch from one firing dynamic to another [24], [25]. On the other hand, direct hardware implementation holds out the promise of faster emulation due to the fact that it is inherently faster than software and also the operation is more parallel. Therefore, efficient digital implementation of neuron models such as Pinsky-Rinzel model has several applications in neuromorphic fields, motivating to implement networks having good stability and high dynamic range [26]-[32]. Analog hardware implementation of neuromorphic circuits has some

M. Amiri is with the Medical Biology Research Center, Kermanshah University of Medical Sciences, Kermanshah, Iran (email:ma_amiri_bme@yahoo.com)

B. Linares-Barranco is with the Microelectronics Institute of Seville, Seville 41092, Spain. 


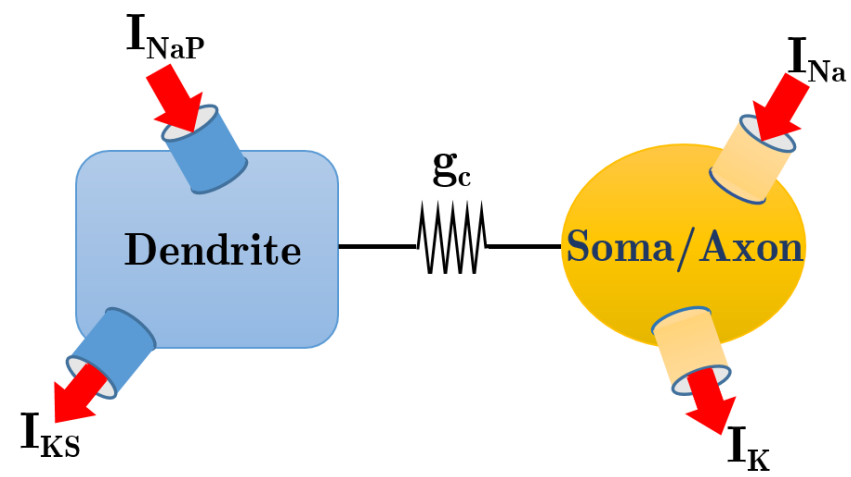

Fig. 1. Two-compartmental model of pyramidal neurons of CA1. The dendrite compartment contains currents that are responsible for bursting behavior and somatic compartment includes currents which cause spiking activity.

limitation such as noise, drift, mismatch and the problem of accuracy of the model [33]-[35]. Therefore, digital implementation with field-programmable gate array, (FPGA) is more reliable and robust [36]-[38]. Recent advances in FPGA technology provide flexibility required for algorithm exploration while meeting performance, power and size constraints. The development of these new technologies to mimic the neuron-biological process has many applications including emulating large scale spiking neural networks.

In this paper, we propose a digital circuit for the simplified Pinsky-Rinzel model (Kepecs and Wang model). First, in order to achieve an optimized implementation in FPGA, the nonlinear differential equations are simplified by a piecewise-linear approximation. Then, the proposed linear model is simulated in MATLAB and the acquired results are compared with the original biophysical model. Next, a digital circuit is designed for the proposed model and is simulated in VIVADO simulation environment. Finally, using several simulations in different conditions, it is demonstrated that the digital circuit follow the dynamical performance of the biophysical Pinsky-Rinzel neuron model simulated in MATLAB and the results are in good agreements.

The rest of the paper is organized as follows: in Section 2, the mathematical model of the simplified Pinsky-Rinzel neuron model is explained. The proposed piecewise-linear model and the digital circuit are described in Section 3. In Section 4, the simulation results are discussed. Finally, Section 5 concludes the paper.

\section{THE SIMPLIFIED PINSKY-RINZEL MODEL}

Kepecs and Wang simplified the Pinsky-Rinzel (P-R) neuron model, a pyramidal cell with two compartments in $\mathrm{CA}$ region [21], [22]. Soma and axon in one compartment include ionic channels for spike generation. Dendrite in the other compartment produces bursting dynamics. Fig. 1 shows that the soma-axon compartment is coupled to the dendrite compartment. $I_{\mathrm{Na}}$ and $I_{\mathrm{K}}$ are the considered currents for somatic compartment and the dendritic compartment includes slow potassium $I_{\mathrm{KS}}$ and a persistent sodium $I_{\mathrm{NaP}}$ currents [22].

This model includes only the minimal biophysical mechanisms necessary to study the phenomenon of complex
TABLE I

PARAMETER VALUeS FOR SimPLIFIEd PINSKY-RINZEL MODEL

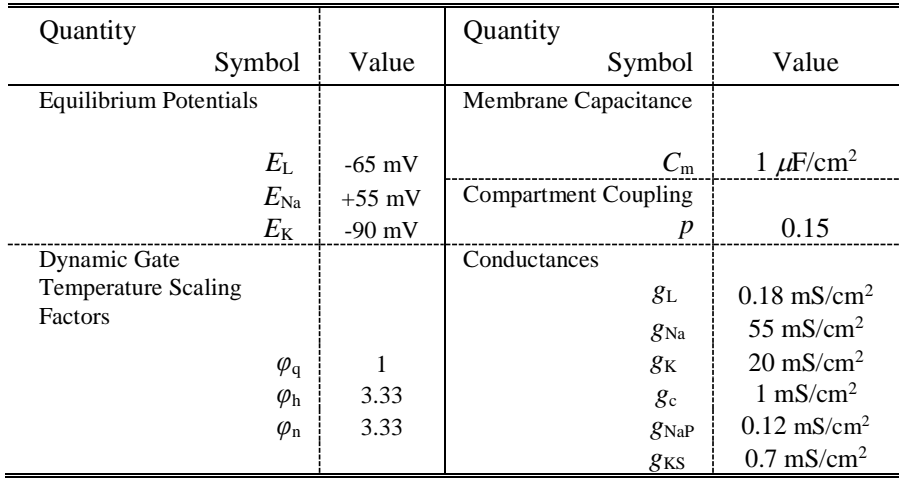

bursting. The simplified Pinsky-Rinzel neuron model is explained by the following equations:

$$
\begin{aligned}
& C_{\mathrm{m}} \frac{d V_{\mathrm{s}}}{d t}=-I_{\mathrm{Na}}-I_{\mathrm{K}}-I_{\text {Leak }}+\frac{I_{\text {link }}}{P}+I_{\text {soma }} \\
& C_{\mathrm{m}} \frac{d V_{\mathrm{d}}}{d t}=-I_{\mathrm{NaP}}-I_{\mathrm{KS}}-I_{\text {Leak }}-\frac{I_{\text {link }}}{(1-P)}+I_{\text {dendrite }} .
\end{aligned}
$$

Where $V_{\mathrm{s}}$ and $V_{\mathrm{d}}$ are the somatic and dendrite membrane potentials (in $\mathrm{mV}$ ) measured with respect to a reference potentials of $-60 \mathrm{mV}$. The currents applied to the soma and dendrite are $I_{\text {soma }}$ and $I_{\text {dendrite, }}$, respectively. In this paper $I_{\text {dendrite }}$ is assumed to be zero [22]. $P$ is the proportion of the cell area taken by soma and $C_{\mathrm{m}}$ is Membrane capacitance. The values of parameters are given in Table I. The ionic currents are given by: $I_{\mathrm{Na}}=g_{\mathrm{Na}} m_{\infty}^{3} h \cdot\left(V_{\mathrm{s}}-E_{\mathrm{Na}}\right)$

$I_{\mathrm{K}}=g_{\mathrm{K}} n^{4} \cdot\left(V_{\mathrm{s}}-E_{\mathrm{K}}\right)$

$I_{\text {leak }}\left(\mathrm{V}_{\mathrm{s}}\right)=g_{\mathrm{L}} \cdot\left(V_{\mathrm{s}}-E_{\mathrm{L}}\right)$

$I_{\text {leak }}\left(\mathrm{V}_{\mathrm{d}}\right)=g_{\mathrm{L}} \cdot\left(V_{\mathrm{d}}-E_{\mathrm{L}}\right)$

$I_{\text {link }}=g_{\mathrm{c}} \cdot\left(V_{\mathrm{d}}-V_{\mathrm{s}}\right)$

$I_{\mathrm{NaP}}=g_{\mathrm{NaP}} l_{\infty}^{3} \cdot\left(V_{\mathrm{d}}-E_{\mathrm{Na}}\right)$

$I_{\mathrm{KS}}=g_{\mathrm{KS}} q \cdot\left(V_{\mathrm{d}}-E_{\mathrm{K}}\right)$

where $E_{\mathrm{L}}, E_{\mathrm{Na}}$, and $E_{\mathrm{K}}$ are Equilibrium potentials, and $g_{\mathrm{Na}}, g_{\mathrm{K}}$, $g_{\mathrm{L}}, g_{\mathrm{c}}, g_{\mathrm{NaP}}, g_{\mathrm{KS}}$ are conductances, which their values are given in Table I. The kinetic equations for the gating variables $h, n$, and $q$ have the form

$\frac{d y}{d t}=\phi_{\mathrm{y}}\left(\frac{y_{\infty}\left(\mathrm{V}_{\mathrm{s}}\right)-y}{\tau_{\mathrm{y}}\left(\mathrm{V}_{\mathrm{s}}\right)}\right)$

where $y=h, n, q$, and $\varphi_{\mathrm{y}}$ are dynamic gate temperature scaling factors, which values are presented in Table I. Gate steady state and time constant equations are given by:

$y_{\infty}=\frac{\alpha_{\mathrm{y}}}{\alpha_{\mathrm{y}}+\beta_{\mathrm{y}}} ; \tau_{y}=\frac{1}{\alpha_{\mathrm{y}}+\beta_{\mathrm{y}}}$, where $(y=h, n)$

$q_{\infty}\left(\mathrm{V}_{\mathrm{d}}\right)=1 /\left(1+\exp \left(-\left(V_{\mathrm{d}}+36\right) / 6.5\right)\right)$

$\tau_{\mathrm{q}}\left(\mathrm{V}_{\mathrm{d}}\right)=\frac{200}{\exp \left(-\left(V_{\mathrm{d}}+55\right) / 30\right)+\exp \left(\left(V_{\mathrm{d}}+55\right) / 30\right)}$

$l_{\infty}\left(\mathrm{V}_{\mathrm{d}}\right)=1 /\left(1+\exp \left(-\left(V_{\mathrm{d}}+57.7\right) / 7.7\right)\right)$

$m_{\infty}=\alpha_{\mathrm{m}} /\left(\alpha_{\mathrm{m}}+\beta_{\mathrm{m}}\right)$.

Finally, rate constant equations are: 
(a)

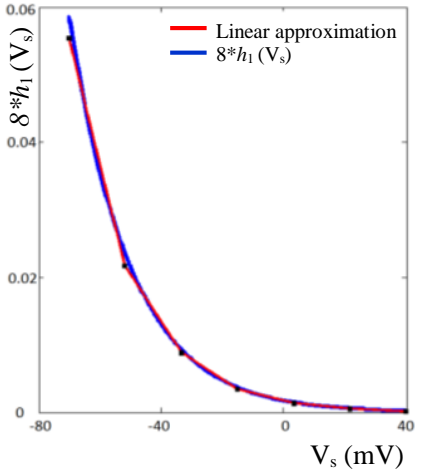

(b)

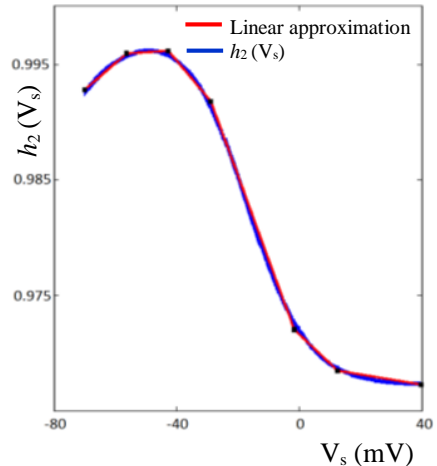

Fig. 2. (a) 6-line segments approximation for $h_{1}\left(\mathrm{~V}_{\mathrm{s}}\right)$. (b) 6-line segments approximation for $h_{2}\left(\mathrm{~V}_{\mathrm{s}}\right)$

$$
\begin{aligned}
& \alpha_{\mathrm{h}}\left(\mathrm{V}_{\mathrm{s}}\right)=0.07 \exp \left(-\left(V_{\mathrm{s}}+47\right) / 20\right) \\
& \beta_{\mathrm{h}}\left(\mathrm{V}_{\mathrm{s}}\right)=1 /\left(\exp \left(-0.1\left(V_{\mathrm{s}}+17\right)\right)+1\right) \\
& \alpha_{\mathrm{n}}\left(\mathrm{V}_{\mathrm{s}}\right)=-0.01\left(V_{\mathrm{s}}+34\right) /\left(\exp \left(-0.1\left(V_{\mathrm{s}}+34\right)\right)-1\right) \\
& \beta_{\mathrm{n}}\left(\mathrm{V}_{\mathrm{s}}\right)=0.125 \exp \left(-\left(V_{\mathrm{s}}+44\right) / 80\right) \\
& \alpha_{m}\left(\mathrm{~V}_{\mathrm{s}}\right)=-0.1\left(V_{\mathrm{s}}+31\right) /\left(\exp \left(-0.1\left(V_{\mathrm{s}}+31\right)\right)-1\right) \\
& \beta_{m}\left(\mathrm{~V}_{\mathrm{s}}\right)=4 \exp \left(-\left(V_{\mathrm{s}}+56\right) / 18\right) .
\end{aligned}
$$

\section{Digital Implementation}

\section{A. The proposed pricewise linear model}

In this section, a piecewise-linear model is presented for the simplified P-R model. First, the continuous time equations, (1) and (2), will be discretized using Euler method which yields (22) and (23). In these equations, dt, the discretizing step size, is set to $0.01(\mathrm{~ms})$.

$$
\begin{array}{r}
V_{\mathrm{s}}[\mathrm{n}+1]=V_{\mathrm{s}}[\mathrm{n}]+\frac{\mathrm{dt}}{C_{\mathrm{m}}} \cdot\left(-I_{\mathrm{Na}}[\mathrm{n}]-I_{\mathrm{K}}[\mathrm{n}]-I_{\text {Leak }}[\mathrm{n}]\right. \\
\left.+\frac{I_{\text {link }}[\mathrm{n}]}{P}+I_{\text {soma }}[\mathrm{n}]\right) \\
V_{\mathrm{d}}[\mathrm{n}+1]=V_{\mathrm{d}}[\mathrm{n}]+\frac{\mathrm{dt}}{C_{\mathrm{m}}} \cdot\left(-I_{\mathrm{NaP}}[\mathrm{n}]-I_{\mathrm{KS}}[\mathrm{n}]-I_{\text {Leak }}[\mathrm{n}]\right. \\
\left.-\frac{I_{\text {link }}[\mathrm{n}]}{(1-P)}+I_{\text {dendrite }}[\mathrm{n}]\right) .
\end{array}
$$

Our digital implementation is based on fixed point operation and depending on the precision which is needed; we consider 32 bits for registers ( 1 bit for sign, 8 bits for integer part and 23 bits for fractional part). In order to discretize (10), it is simplified as follow:

$y=y_{\infty}-\left(y_{\infty}-y_{0}\right) \cdot \exp (-(\mathrm{t} \cdot \phi) / \tau)$

where $y=h, n$, and $q$. By discretizing (24), we can get $y[\mathrm{n}+1]=y_{\infty}[\mathrm{n}]-\left(y_{\infty}[\mathrm{n}]-y[\mathrm{n}]\right) \cdot \exp (-(\mathrm{dt} \cdot \phi) / \tau[\mathrm{n}])$.

To obtain $V_{\mathrm{s}}$, individual currents should be calculated. We start with $I_{\mathrm{Na}}$, which has the following discrete equation

$$
I_{\mathrm{Na}}[\mathrm{n}+1]=g_{\mathrm{Na}} \cdot m_{\infty}^{3}[\mathrm{n}] \cdot h[\mathrm{n}] \cdot\left(V_{\mathrm{s}}[\mathrm{n}]-E_{\mathrm{Na}}\right) \text {. }
$$

For $I_{\mathrm{Na}}[\mathrm{n}+1]$, we substitute $y$ from (25) into $h$, to get $h[\mathrm{n}]$, (27), which its steady and transient responses are separated in (28).
TABLE II

THE PARAMETER VALUES OF INDIVIDUAL LINES FOR THE 6-LINE SEGMENTS APPROXIMATION OF $8 * h_{1}\left(\mathrm{~V}_{\mathrm{S}}\right)=\mathrm{A}_{1} * V_{\mathrm{S}}+\mathrm{B}_{1}$

\begin{tabular}{lcc}
\hline \hline Region of $\mathrm{V}_{\mathrm{s}}(\mathrm{mV})$ & $\mathrm{A}_{1}$ & $\mathrm{~B}_{1}$ \\
\hline$[-70,-54.3]$ & -1.9666 & -0.0814 \\
$(-54.3,-38.6]$ & -0.8715 & -0.0220 \\
$(-38.6,-22.9]$ & -0.4056 & -0.0040 \\
$(-22.9,-7.1]$ & -0.1824 & 0.0011 \\
$(-7.1,8.6]$ & -0.0829 & 0.0018 \\
$(8.6,40]$ & -0.0273 & 0.0013 \\
\hline \hline
\end{tabular}

TABLE III

THE PARAMETER VALUES OF INDIVIDUAL LiNES FOR THE 6-LINE SEGMENTS APPROXIMATION OF $h_{2}\left(V_{\mathrm{S}}\right)=\mathrm{A}_{2} * V_{\mathrm{S}}+\mathrm{B}_{2}$

\begin{tabular}{lcc}
\hline \hline \multicolumn{2}{c}{$\mathrm{A}_{2}$} & $\mathrm{~B}_{2}$ \\
\hline Region of $\mathrm{V}_{\mathrm{S}}(\mathrm{mV})$ & & 1.0087 \\
$(-70,-56.3]$ & 0.2272 & 0.9968 \\
$(-42.5,-42.5]$ & 0.0160 & 0.9827 \\
$(-28.8,-1.3]$ & -0.3159 & 0.9712 \\
$(-1.3,12.5]$ & -0.7171 & 0.9717 \\
$(12.5,40]$ & -0.2566 & 0.9691 \\
\hline \hline
\end{tabular}

$$
\begin{aligned}
h[\mathrm{n}+1]= & h_{\infty}[\mathrm{n}]\left(1-\exp \left(-\left(\mathrm{dt} \cdot \phi_{\mathrm{h}}\right) / \tau_{\mathrm{h}}[\mathrm{n}]\right)\right) \\
& +h[\mathrm{n}] \cdot \exp \left(-\left(\mathrm{dt} \cdot \phi_{\mathrm{h}}\right) / \tau_{\mathrm{h}}[\mathrm{n}]\right)
\end{aligned}
$$

$h[\mathrm{n}+1]=h_{1}[\mathrm{n}]+h[\mathrm{n}] \cdot h_{2}[\mathrm{n}]$

where $h_{1}[\mathrm{n}]$ and $h_{2}[\mathrm{n}]$ are described as follows:

$$
\begin{aligned}
h_{1}[\mathrm{n}]= & \left(\frac{\alpha_{\mathrm{h}}[\mathrm{n}]}{\alpha_{\mathrm{h}}[\mathrm{n}]+\beta_{\mathrm{h}}[\mathrm{n}]}\right) \\
& \cdot\left(1-\exp \left(-\mathrm{dt} \cdot \phi_{\mathrm{h}} \cdot\left(\alpha_{\mathrm{h}}[\mathrm{n}]+\beta_{\mathrm{h}}[\mathrm{n}]\right)\right)\right) \\
h_{2}[\mathrm{n}]= & h[\mathrm{n}] \cdot \exp \left(-\mathrm{dt} \cdot \phi_{\mathrm{h}} \cdot\left(\alpha_{\mathrm{h}}[\mathrm{n}]+\beta_{\mathrm{h}}[\mathrm{n}]\right)\right) .
\end{aligned}
$$

One of the bottlenecks in digital hardware implementation is the presence of nonlinear equations, such as exponential functions in (29) and (30). Using look up tables, which is one of the traditional methods, to approximate these nonlinear functions need many comparators and several registers for saving data. In this paper, by using a piecewise linear approximation, nonlinear parts are eliminated and replaced with first order functions which preserve the dynamical characteristics of the original nonlinear systems. Hence, it is possible to implement the simplified P-R neuron model in a digital platform. An exhaustive search algorithm is utilized to find the best parameter values of the line segments which lead to the minimum error. As shown in Fig. 2(b), $h_{2}$ is approximated with 6 lines, too.

Range of $V_{\mathrm{s}}$ is small in comparison to range of $h_{l}$. Therefore, we multiply $h_{l}$ by 8 in order to obtain good accuracy, and then approximate it by 6-line segments, as shown in Fig. 2(a). Finally, to obtain the exact values of $h_{l}$, it is shifted to right for 3 digits.

In our digital implementation, a memory register stores the outputs such as current, somatic and dendrite voltages. The value of $A_{\mathrm{i}}$ and $B_{i}$ with respect to the input is listed in Table II and Table III. Given linear approximation, the functions are implemented by using simple blocks such as adder, shifter and so on; therefore, the cost of hardware implementation reduces remarkably. Corresponding line parameters of $h_{1}[\mathrm{n}]$ and $h_{2}[\mathrm{n}]$ are listed in Table II and Table III, respectively. 
(a)

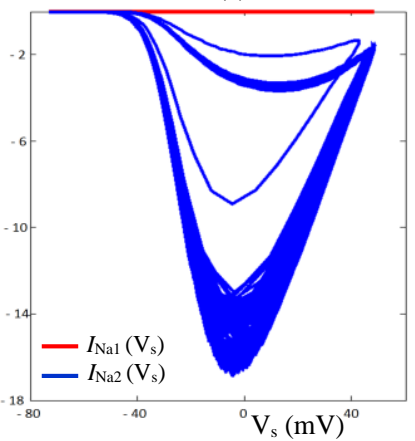

Fig. 3. (a) Comparison between term 1 and term 2 of $I_{\mathrm{Na}}$ function, (b) 9-line segments approximation for $I_{\mathrm{Na} 2}\left(\mathrm{~V}_{\mathrm{s}}\right)$

(a)

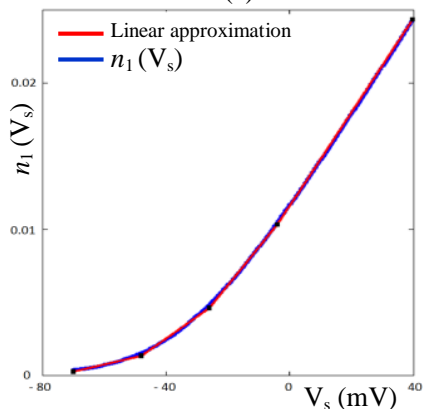

(b)

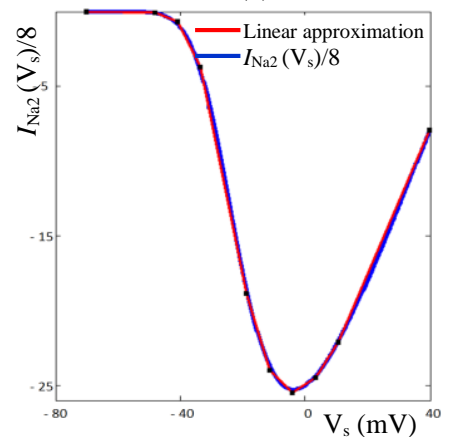

(b)

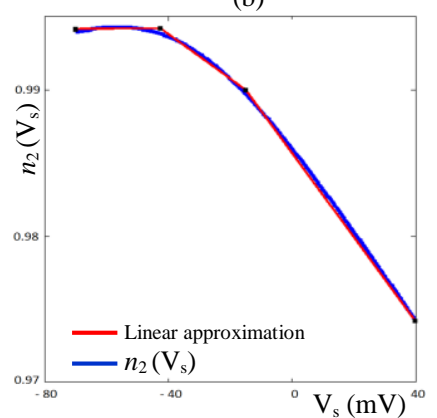

Fig. 4. (a) 4-line segments approximation for $n_{1}\left(\mathrm{~V}_{\mathrm{s}}\right)$. (b) 3-line segments approximation for $n_{2}\left(\mathrm{~V}_{\mathrm{s}}\right)$.

A fter computing $h[\mathrm{n}]$, we should approximate the $I_{\mathrm{Na}}$ function. For this purpose, substituting (26) into the (31) and (32), yields

$$
\begin{array}{r}
I_{\mathrm{Na}}[\mathrm{n}+1]=g_{\mathrm{Na}} \cdot m_{\infty}^{3}[\mathrm{n}] \cdot\left(h_{1}[\mathrm{n}]+h[\mathrm{n}] \cdot h_{2}[\mathrm{n}]\right) \\
\cdot\left(V_{\mathrm{s}}[\mathrm{n}]-E_{\mathrm{Na}}\right)
\end{array}
$$

$I_{\mathrm{Na}}[\mathrm{n}+1]=I_{\mathrm{Na} 1}[\mathrm{n}]+h[\mathrm{n}] \cdot I_{\mathrm{Na} 2}[\mathrm{n}]$.

Since $I_{\mathrm{Na} 1}[\mathrm{n}]$ is negligible compared to $\left(h[\mathrm{n}] \cdot I_{\mathrm{Na} 2}[\mathrm{n}]\right)$ it can be ignored in (32) as shown in Fig. 3(a). Hence we can obtain:

$$
I_{\mathrm{Na}}[\mathrm{n}+1] \simeq h[\mathrm{n}] \cdot I_{\mathrm{Na} 2}[\mathrm{n}] .
$$

Because we consider 8 bits for the integer part of numbers, it is necessary to scale $I_{\mathrm{Na} 2}[\mathrm{n}]$ (dividing by 8 ), and then we approximate $I_{\mathrm{Na} 2}[\mathrm{n}$ ] by 9-line segments due to its highly nonlinearity, as shown in Fig. 3(b). At the end, we shift $I_{\mathrm{Na} 2}$ left by 3 digits to obtain the exact values. The parameter values of the resulting lines are listed in Table IV.

Next, $I_{\mathrm{K}}$ must be computed. In this way, $n$ is substituted in (25); therefore, (34) is obtained which steady and transient states are as follow:

$$
\begin{array}{r}
n[\mathrm{n}+1]=n_{\infty}[\mathrm{n}]\left(1-\exp \left(-\left(\mathrm{dt} \cdot \phi_{\mathrm{n}}\right) / \tau_{\mathrm{n}}[\mathrm{n}]\right)\right) \\
+n[\mathrm{n}] \cdot \exp \left(-\left(\mathrm{dt} \cdot \phi_{\mathrm{n}}\right) / \tau_{\mathrm{n}}[\mathrm{n}]\right)
\end{array}
$$

$n[\mathrm{n}+1]=n_{1}[\mathrm{n}]+n[\mathrm{n}] \cdot n_{2}[\mathrm{n}]$.

In (34) and (35), $n_{1}[\mathrm{n}]$ and $n_{2}[\mathrm{n}]$ are

$$
n_{1}[\mathrm{n}]=\left(\alpha_{\mathrm{n}}[\mathrm{n}] /\left(\alpha_{\mathrm{n}}[\mathrm{n}]+\beta_{\mathrm{n}}[\mathrm{n}]\right)\right)
$$

$$
\cdot\left(1-\exp \left(-\mathrm{dt} \cdot \phi_{\mathrm{n}} \cdot\left(\alpha_{\mathrm{n}}[\mathrm{n}]+\beta_{\mathrm{n}}[\mathrm{n}]\right)\right)\right)
$$

$n_{2}[\mathrm{n}]=n[\mathrm{n}] \cdot \exp \left(-\mathrm{dt} \cdot \phi_{n} \cdot\left(\alpha_{n}[\mathrm{n}]+\beta_{n}[\mathrm{n}]\right)\right)$.

$n_{1}[\mathrm{n}]$ and $n_{2}[\mathrm{n}]$ are approximated with 4-line and 3-line segments, respectively, as shown in Fig. 4. The parameter
TABLE IV

THE PARAMETER VALUES OF INDIVIDUAL LINES FOR THE 9-LiNE SEGMENTS APPROXIMATION OF $I_{\mathrm{N} a 2}\left(\mathrm{~V}_{\mathrm{S}}\right) / 8=\mathrm{A}_{3} * V_{\mathrm{S}}+\mathrm{B}_{3}$

\begin{tabular}{lcc}
\hline \hline Region of $\mathrm{V}_{\mathrm{s}}(\mathrm{mV})$ & $\mathrm{A}_{3}$ & $\mathrm{~B}_{3}$ \\
\hline$[-70,-48.0]$ & -0.4610 & -0.0323 \\
$(-48.0,-40.7]$ & -10.4597 & -0.5122 \\
$(-40.7,-33.3]$ & -51.7974 & -2.1933 \\
$(-33.3,-18.7]$ & -129.1278 & -4.7710 \\
$(-18.7,-11.3]$ & -87.4004 & -3.9920 \\
$(-11.3,-4]$ & -25.5956 & -3.2916 \\
$(-4,3.3]$ & 16.9626 & -3.1214 \\
$(3.3,10.7]$ & 41.0090 & -3.2015 \\
$(10.7,40]$ & 60.4787 & -3.4092 \\
\hline \hline
\end{tabular}

TABLE V

THE PARAMETER VALUES OF INDIVIDUAL LINES FOR THE 4-LINE SEGMENTS APPROXIMATION OF $n_{1}\left(\mathrm{~V}_{\mathrm{S}}\right)=\mathrm{A}_{4} * V_{\mathrm{S}}+\mathrm{B}_{4}$

\begin{tabular}{lcc}
\hline Region of $\mathrm{V}_{\mathrm{s}}(\mathrm{mV})$ & $\mathrm{A}_{4}$ & $\mathrm{~B}_{4}$ \\
\hline$[-70,-48]$ & 0.0500 & 0.0037 \\
$(-48,-26]$ & 0.1489 & 0.0085 \\
$(-26,-4]$ & 0.2604 & 0.0114 \\
$(-4,40]$ & 0.3179 & 0.0116 \\
\hline \hline
\end{tabular}

TABLE VI

THE PARAMETER VALUES OF INDIVIDUAL LINES FOR THE 3-LINE SEGMENTS APPROXIMATION OF $n_{2}\left(\mathrm{~V}_{\mathrm{S}}\right)=\mathrm{A}_{5} * V_{\mathrm{S}}+\mathrm{B}_{5}$

\begin{tabular}{lcc}
\hline \hline Region of $\mathrm{V}_{\mathrm{s}}(\mathrm{mV})$ & $\mathrm{A}_{5}$ & $\mathrm{~B}_{5}$ \\
\hline$[-70,-42.5]$ & 0 & 0.9942 \\
$(-42.5,-15]$ & -0.1514 & 0.9877 \\
$(-15,40]$ & -0.2865 & 0.9857 \\
\hline \hline
\end{tabular}

values of the resulted lines are given in Table $\mathrm{V}$ and Table VI, respectively. After calculating $n[\mathrm{n}], I_{\mathrm{K}}[\mathrm{n}]$ will be discretized as

$I_{\mathrm{K}}[\mathrm{n}+1]=g_{\mathrm{K}} \cdot(n[\mathrm{n}])^{4} \cdot\left(V_{\mathrm{s}}[\mathrm{n}]-E_{\mathrm{K}}\right)$.

Similarly, $I_{\text {leak }}$ and $I_{\text {link }}$ will be discretized

$I_{\text {leak }}[\mathrm{n}]=g_{\mathrm{L}} \cdot\left(V[\mathrm{n}]-E_{\mathrm{L}}\right) ; \quad$ where $\mathrm{V}=V_{\mathrm{s}}, V_{\mathrm{d}}$

$I_{\text {link }}[\mathrm{n}]=g_{\mathrm{c}} \cdot\left(V_{\mathrm{d}}[\mathrm{n}]-V_{\mathrm{s}}[\mathrm{n}]\right)$.

To calculate $V_{\mathrm{d}}[\mathrm{n}+1]$, the dynamical equation of the $I_{\mathrm{NaP}},(8)$, should be discretized, consequently, it is approximated by 8 line segments, as presented in Fig. 5. The parameter values of the $I_{\mathrm{NaP}}$ are given in Table VII. The $I_{\mathrm{NaP}}$ current can be written as follow:

$I_{\mathrm{NaP}}[\mathrm{n}+1]=\mathrm{A}_{6} \cdot V_{\mathrm{d}}[\mathrm{n}]+\mathrm{B}_{6}$

Calculating $I_{\mathrm{KS}}[\mathrm{n}+1]$ is similar to $I_{\mathrm{Na}}[\mathrm{n}+1]$. Using (25), we can obtain $\mathrm{q}[\mathrm{n}]$ which steady and transient states are

$$
\begin{aligned}
q[\mathrm{n}+1]= & q_{\infty}[\mathrm{n}]\left(1-\exp \left(-\left(\mathrm{dt} \cdot \phi_{\mathrm{q}}\right) / \tau_{\mathrm{q}}[\mathrm{n}]\right)\right) \\
& +q[\mathrm{n}] \cdot \exp \left(-\left(\mathrm{dt} \cdot \phi_{\mathrm{q}}\right) / \tau_{\mathrm{q}}[\mathrm{n}]\right)
\end{aligned}
$$

$q[\mathrm{n}+1]=q_{1}[\mathrm{n}]+q[\mathrm{n}] \cdot q_{2}[\mathrm{n}]$

$q_{1}[\mathrm{n}]=\left(\alpha_{\mathrm{q}}[\mathrm{n}] /\left(\alpha_{\mathrm{q}}[\mathrm{n}]+\beta_{\mathrm{q}}[\mathrm{n}]\right)\right)$

$$
\cdot\left(1-\exp \left(-\mathrm{dt} \cdot \phi_{\mathrm{q}} \cdot\left(\alpha_{\mathrm{q}}[\mathrm{n}]+\beta_{\mathrm{q}}[\mathrm{n}]\right)\right)\right)
$$

$q_{2}[\mathrm{n}]=q[\mathrm{n}] \cdot \exp \left(-\mathrm{dt} \cdot \phi_{\mathrm{q}} \cdot\left(\alpha_{\mathrm{q}}[\mathrm{n}]+\beta_{\mathrm{q}}[\mathrm{n}]\right)\right)$

Range of $q_{1}$ is small in comparison to range of $V_{\mathrm{d}}$. Therefore, we multiply $q_{1}$ by 16 in order to reach higher accuracy, and then approximate it by 6-line segments, as shown in Fig. 6(a). Finally, in order to obtain the exact values of $q_{1}$, it is shifted to right for 4 digits. Also, $q_{2}$ is approximated by 6-line segments, 


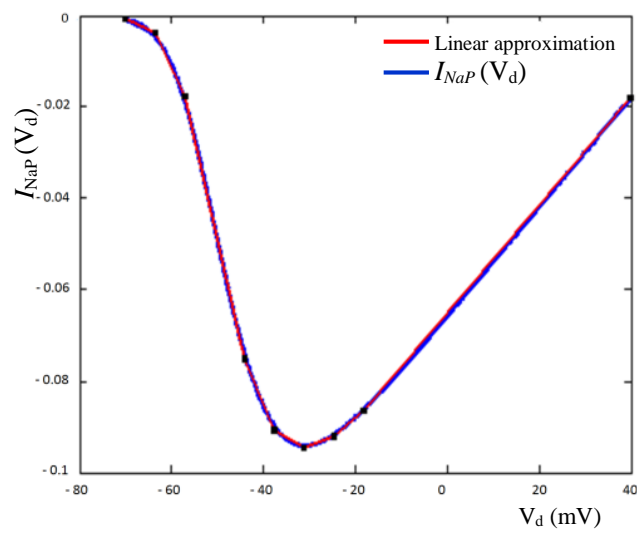

Fig. 5. 8-line segments approximation for $I_{\mathrm{NaP}}\left(\mathrm{V}_{\mathrm{d}}\right)$ (a)

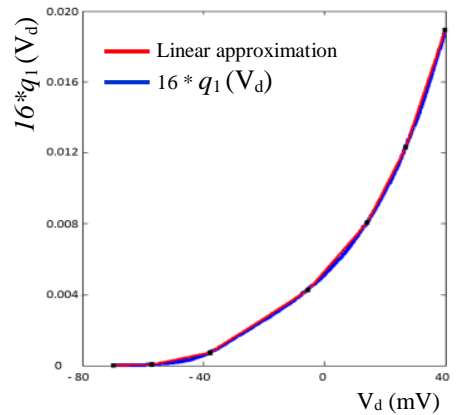

(b)

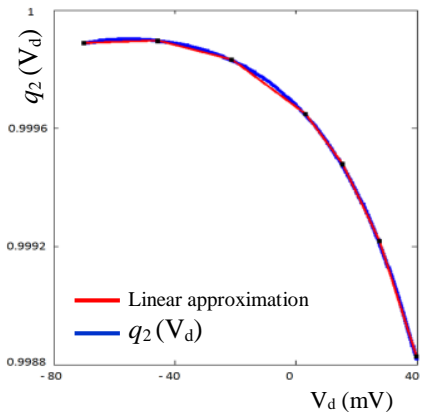

Fig. 6. (a) 6-line segments approximation for $q_{1}\left(\mathrm{~V}_{\mathrm{d}}\right)$. (b) 6-line segments approximation for $q_{2}\left(\mathrm{~V}_{\mathrm{d}}\right)$. (a)

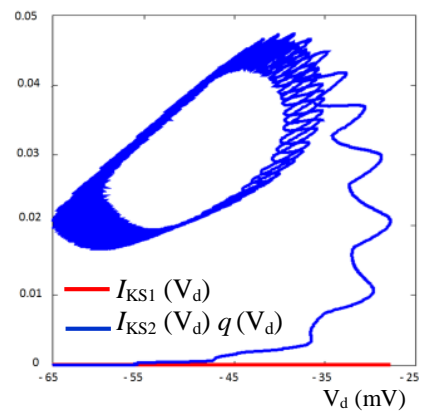

(b)

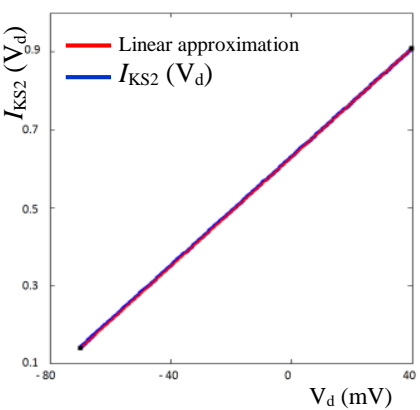

Fig. 7. (a) Comparison between term 1 and term 2 of $I_{\mathrm{KS}}\left(\mathrm{V}_{\mathrm{d}}\right)$ function. (b) 1-line segment approximation for $I_{\mathrm{KS} 2}\left(\mathrm{~V}_{\mathrm{d}}\right)$

as shown in Fig. 6(b). Next, we can approximate the $I_{\mathrm{Ks}}$. For this purpose, we can substitute (9) into (46) and (47).

$I_{\mathrm{KS}}[\mathrm{n}+1]=g_{\mathrm{KS}} \cdot\left(q_{1}[\mathrm{n}]+q[\mathrm{n}] \cdot q_{2}[\mathrm{n}]\right) \cdot\left(V_{\mathrm{d}}[\mathrm{n}]-E_{\mathrm{K}}\right)$

$I_{\mathrm{KS}}[\mathrm{n}+1]=I_{\mathrm{KS} 1}[\mathrm{n}]+q[\mathrm{n}] \cdot I_{\mathrm{KS} 2}[\mathrm{n}]$

$I_{\mathrm{KS} 1}[\mathrm{n}]$ can be ignored since its value is negligible compared to $\left(q[\mathrm{n}] * I_{\mathrm{KS} 2}[\mathrm{n}]\right)$, as shown in Fig. $7(\mathrm{a})$. Therefore we can obtain:

$I_{\mathrm{KS}}[\mathrm{n}+1] \simeq q[\mathrm{n}] \cdot I_{\mathrm{KS} 2}[\mathrm{n}]$

$I_{\mathrm{KS} 2}[\mathrm{n}]$ is approximated by 1-line segment too, as shown in Fig. 7(b). Table $X$ shows the parameter values of this line.

\section{B. The proposed digital circuit}

To overcome the problems of analog fabrication without sacrificing area and power budgets, in this paper, a digital implementation is used. In this way, the proposed piecewise linear model enables us to design architecture for implementation on the FPGA. The required steps to get the
TABLE VII

The Parameter VAlues of INDividual Lines For THE 8-Line SEgments APPROXIMATION OF $I_{\mathrm{N} a \mathrm{P}}\left(\mathrm{V}_{d}\right)=\mathrm{A}_{6} * V_{d}+\mathrm{B}_{6}$

\begin{tabular}{lcc}
\hline \hline Region of $\mathrm{V}_{\mathrm{d}}(\mathrm{mV})$ & $\mathrm{A}_{6}$ & $\mathrm{~B}_{6}$ \\
\hline$[-70,-63.5]$ & -0.5103 & -0.0362 \\
$(-63.5,-57.1]$ & -2.1664 & -0.1414 \\
$(-57.1,-44.1]$ & -4.4365 & -0.2709 \\
$(-44.1,-37.6]$ & -2.4086 & -0.1814 \\
$(-37.6,-31.2]$ & -0.6015 & -0.1134 \\
$(-31.2,-24.7]$ & 0.4028 & -0.0821 \\
$(-24.7,-18.2]$ & 0.8673 & -0.0706 \\
$(-18.2,40]$ & 1.1752 & -0.0650 \\
\hline \hline
\end{tabular}

TABLE VIII

THE PARAMETER VALUES OF INDIVIDUAL LINES FOR THE 6-LINE SEGMENTS APPROXIMATION OF $16 * q_{1}\left(\mathrm{~V}_{d}\right)=\mathrm{A}_{7} * V_{d}+\mathrm{B}_{7}$

\begin{tabular}{lcc}
\hline \hline Region of $\mathrm{V}_{\mathrm{d}}(\mathrm{mV})$ & $\mathrm{A}_{7}$ & $\mathrm{~B}_{7}$ \\
\hline$[-70,-57.1]$ & 0.0031 & 00002 \\
$(-57.1,-37.6]$ & 0.0351 & 0.0021 \\
$(-37.6,-5.3]$ & 0.1099 & 0.0049 \\
$(-5.3,14.1]$ & 0.1940 & 0.0053 \\
$(14.1,27.1]$ & 0.3305 & 0.0034 \\
$(27.1,40]$ & 0.5104 & -0.0015 \\
\hline \hline
\end{tabular}

TABLE IX

THE PARAMETER VALUES OF INDIVIDUAL LiNES FOR THE 6-LINE SEgMENTS APPROXIMATION OF $q_{2}\left(\mathrm{~V}_{d}\right)=\mathrm{A}_{8} * V_{d}+\mathrm{B}_{8}$

\begin{tabular}{lcc}
\hline \hline Region of $\mathrm{V}_{\mathrm{d}}(\mathrm{mV})$ & $\mathrm{A}_{8}$ & $\mathrm{~B}_{8}$ \\
\hline$[-70,-45.6]$ & 0 & 0.9999 \\
$(-45.6,-21.1]$ & -0.0027 & 0.9998 \\
$(-21.1,3.3]$ & -0.0075 & 0.9997 \\
$(3.3,15.6]$ & -0.0140 & 0.9997 \\
$(15.6,27.8]$ & -0.0211 & 0.9998 \\
$(27.8,40]$ & -0.0321 & 1.0001 \\
\hline \hline
\end{tabular}

TABLE X

THE PARAMETER VALUES OF INDIVIDUAL LiNES FOR THE 1-LiNE SEGMENT APPROXIMATION OF $I_{\mathrm{KS} 2}\left(\mathrm{~V}_{d}\right)=\mathrm{A}_{9} * V_{d}+\mathrm{B}_{9}$

\begin{tabular}{lcc}
\hline \hline Region of $\mathrm{V}_{\mathrm{d}}(\mathrm{mV})$ & $\mathrm{A}_{9}$ & $\mathrm{~B}_{9}$ \\
\hline$[-70,40]$ & 7 & 0.6296 \\
\hline \hline
\end{tabular}

response of individual function are showed in Fig. 8, 9, 10, and 11 , respectively. As mentioned earlier, we consider 32 bits for registers ( 1 bit for sign, 8 bits for integer part and 23 bits for fractional part). Therefore, inputs and the corresponding outputs of our multipliers, adders and subtractions are 32 bits.

We used FPGA for hardware implementation. By providing an array of logic components that can be easily configured in a desired mode, FPGAs are reconfigurable devices for implementation of digital systems, [8]. Recent studies investigated that FPGA provide an appropriate platform for designing neuromorphic systems [29]. The digital circuit was simulated and synthesized using VIVADO, resulting a maximum clock frequency of $318.173 \mathrm{MHz}$. The resource utilization of the FPGA implementations is summarized in Table XI.

\section{Error calculation}

Error between the proposed models and the original P-R model is defined as Root Mean Square Error (RMSE), and calculated by (49). Furthermore, we calculate normalized RMSE (NRMSE) as (50). In (50), $\mathrm{Y}_{\text {real }}$ defines the original 
(a)

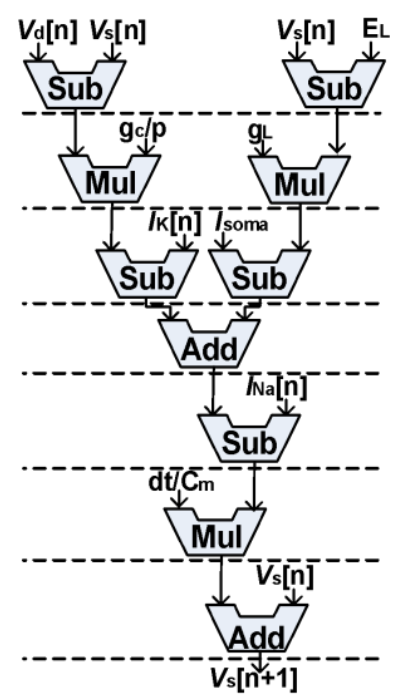

(b)

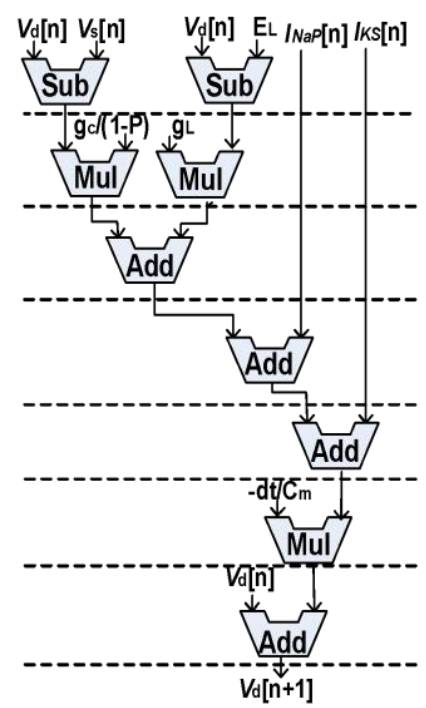

(a)

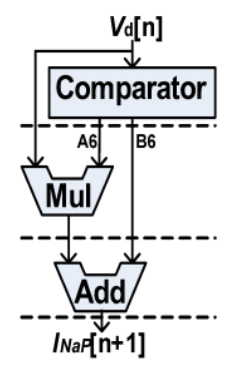

(b)

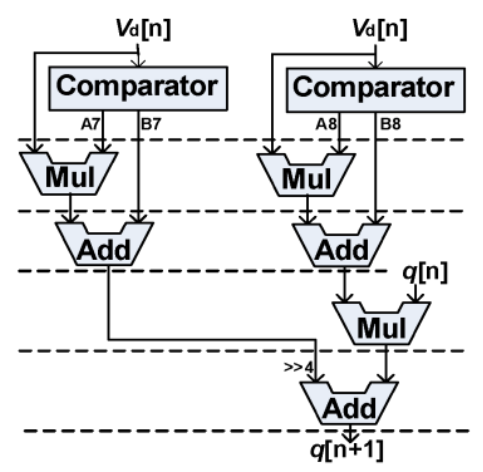

(c)

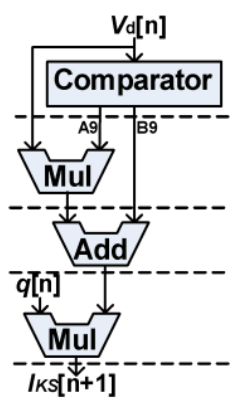

Fig. 11. Scheduling diagram for proposed model. (a) The persistent sodium current for dendrite compartment, $I_{\mathrm{NaP}}[\mathrm{n}]$. (b) $q[\mathrm{n}]$. (c) The slow potassium current for dendrite compartment, $I_{\mathrm{KS}}[\mathrm{n}]$.

TABLE XI

LOW-LEVEL DEVICE UTILIZATION SUMMARY

\begin{tabular}{lcc}
\hline \hline Slice logic utilization & Used & Available \\
\hline Number of slice LUTs & 23,293 & 53,200 \\
Number of bonded IOBs & 9 & 200 \\
Number of slice registers & 172 & 106,400 \\
\hline \hline
\end{tabular}

TABLE XII

THE RMSE AND NRMSE FOR ORIGINAL AND PROPOSED FUNCTIONS

\begin{tabular}{lcc}
\hline \hline Function & RMSE & NRMSE \\
\hline$h_{1}$ & $5.1418 \mathrm{e}-05$ & 0.0070 \\
$h_{2}$ & $2.6482 \mathrm{e}-04$ & 0.0092 \\
$I_{\mathrm{Na} 2}$ & 0.2079 & 0.0082 \\
$n_{1}$ & $7.5419 \mathrm{e}-05$ & 0.0031 \\
$n_{2}$ & $2.0424 \mathrm{e}-04$ & 0.0102 \\
$I_{\mathrm{NaP}}$ & $5.1601 \mathrm{e}-04$ & 0.0055 \\
$q_{1}$ & $8.6683 \mathrm{e}-06$ & 0.0073 \\
$q_{2}$ & $9.5981 \mathrm{e}-06$ & 0.0088 \\
$I_{\mathrm{KS} 2}$ & $1.3311 \mathrm{e}-04$ & $1.7314 \mathrm{e}-04$ \\
\hline \hline & $\mathrm{RMSE}$ & \\
$\mathrm{NRMSE}\left(\mathrm{Y}_{\text {real }}, \mathrm{Y}_{\text {approx }}\right)=\frac{}{\mathrm{Y}_{\max }-\mathrm{Y}_{\min }}$ &
\end{tabular}

\section{Simulation Results}

In this section, software and hardware implementation results are discussed. Indeed, the primary objective is to examine the feasibility of FPGA implementation of the model and to show that hardware can reproduce the model responses. By adjusting $\mathrm{P}, I_{\text {soma }}$ and $g_{\mathrm{c}}$, different patterns of simplified Pinsky-Rinzel model can be obtained. In the first set of simulations, bursting activities is examined. In simulation shown in Fig. 12, $g_{\mathrm{c}}=1$, $p=0.15$ and for (a),(b),(c) $I_{\text {soma }}=3$ and for (d),(e),(f) $I_{\text {soma }}=19.7$. 
(a)
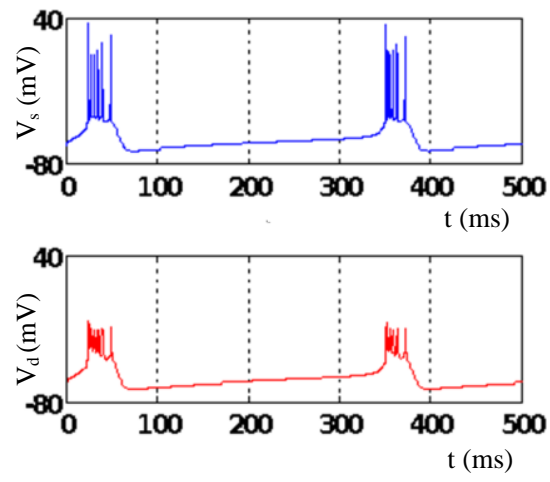

(d)
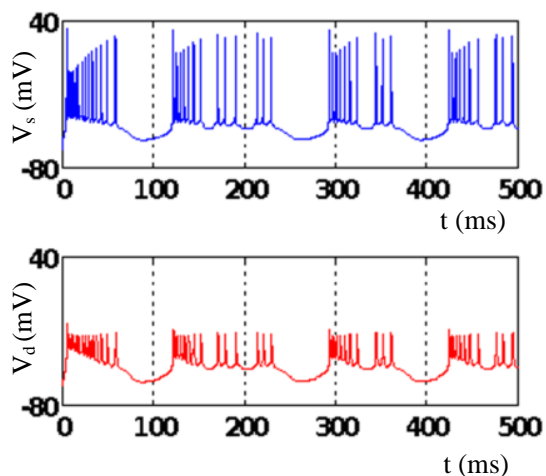

(b)
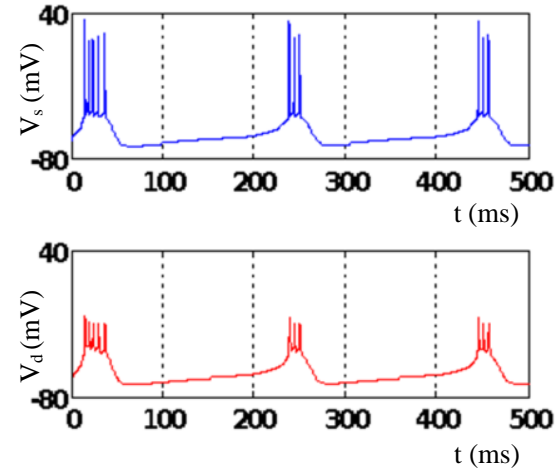

(e)
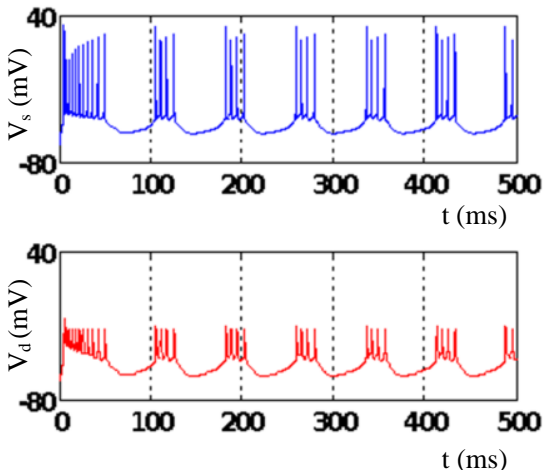

(c)
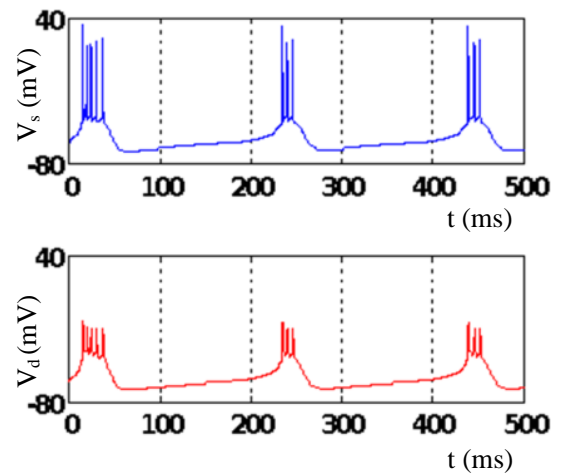

(f)
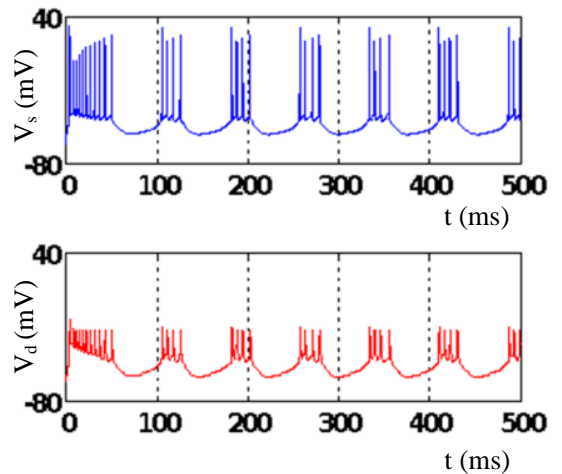

Fig. 12. The time response of the neuron membrane potential of soma $\left(V_{\mathrm{s}}\right)$ and dendrite $\left(V_{\mathrm{d}}\right)$ components in $\mathrm{mV}$. (a), (d) MATLAB simulations of the original simplified P-R model. (b), (e) MATLAB simulations of the proposed piece-wise linear model. (c), (f) VIVADO simulation of the designed digital circuit. In these simulations $\left(g_{\mathrm{c}}, p\right)=(1,0.15)$ and in (a), (b), (c) $I_{\text {soma }}=3$ and in (d), (e), (f) $I_{\text {soma }}=19.7$. The first and the third panels show the bursting activities of somatic voltage. The second and the forth panels show the bursting activities of dendrite voltage.

(a)
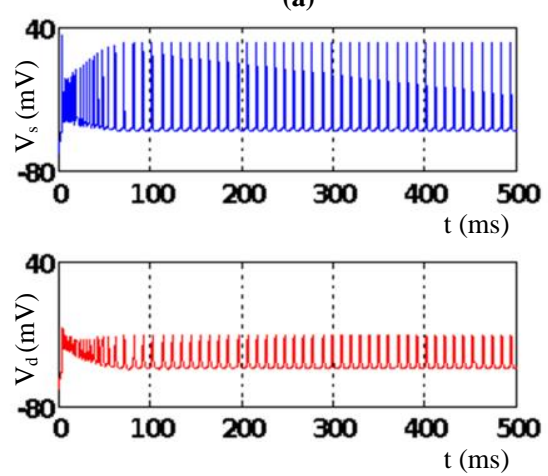

(d)
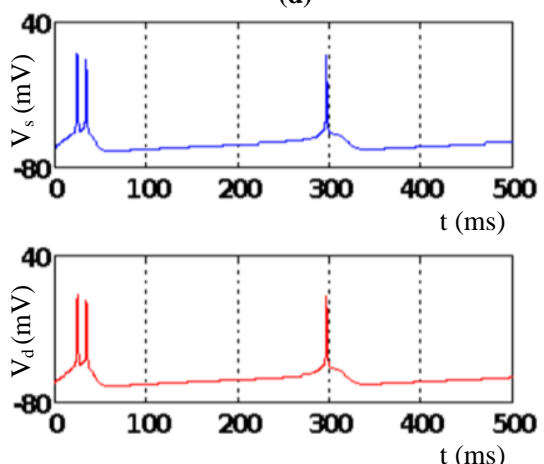

(b)
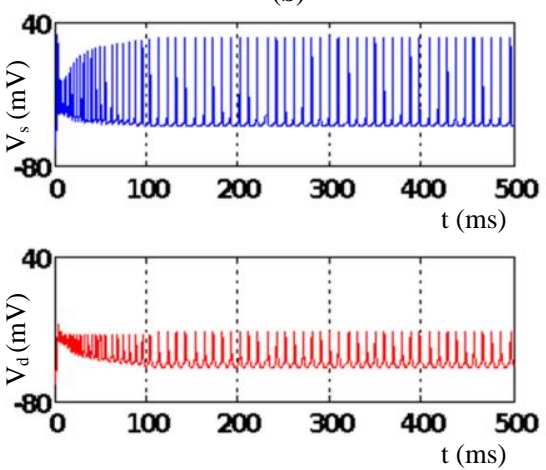

(e)
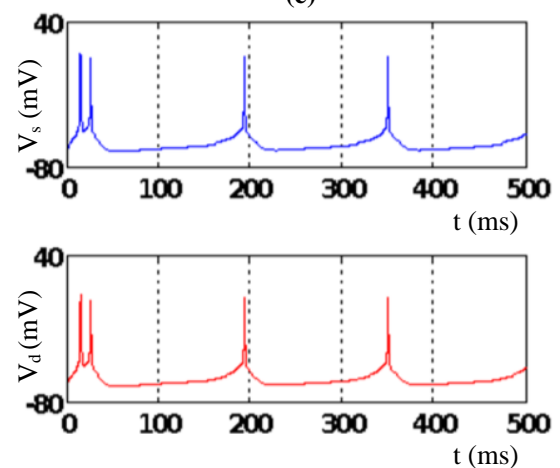

(c)
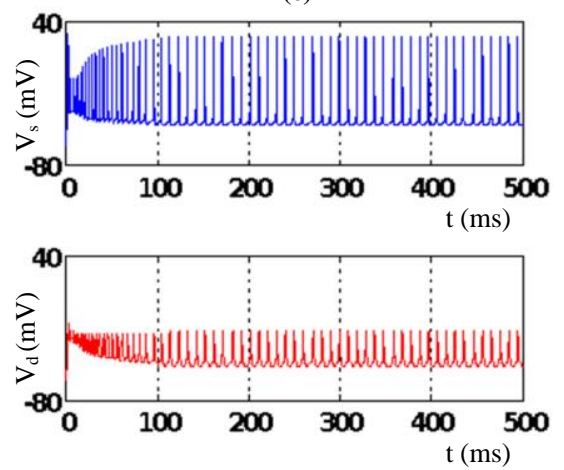

(f)
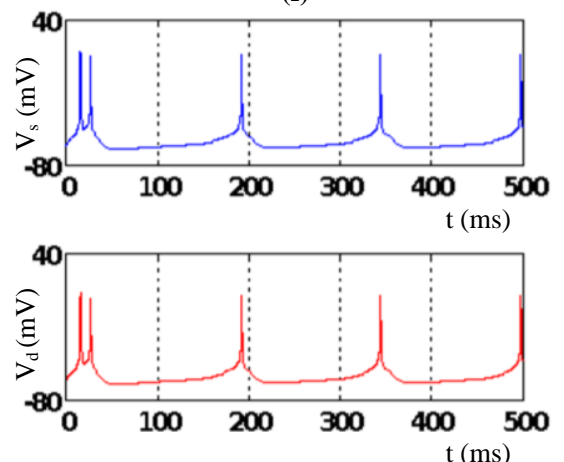

Fig. 13. The time response of the neuron membrane potential of soma $\left(V_{\mathrm{s}}\right)$ and dendrite $\left(V_{\mathrm{d}}\right)$ components in $\mathrm{mV}$. (a),(d) MATLAB simulations of the original simplified P-R model. (b),(e) MATLAB simulations of the proposed piecewise linear model. (c), (f) VIVADO simulation of the designed digital circuit. In these simulations $p=0.15$ and in (a) $\left(g_{\mathrm{c}}, I_{\text {soma }}\right)=(1,23)$, in (b), (c) $\left(g_{\mathrm{c}}, I_{\text {soma }}\right)=(1,34)$ and in (d), (e), (f) $\left(g_{\mathrm{c}}, I_{\text {soma }}\right)=(5,3)$. The first and the third panels show the bursting activities of somatic voltage. The second and the forth panels show the bursting activities of dendrite voltage. 
(a)
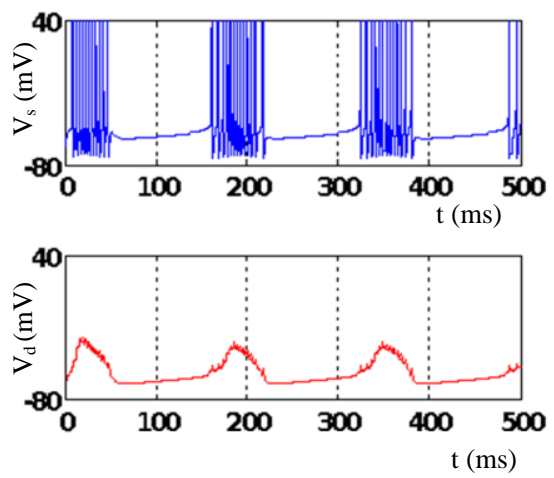

(d)
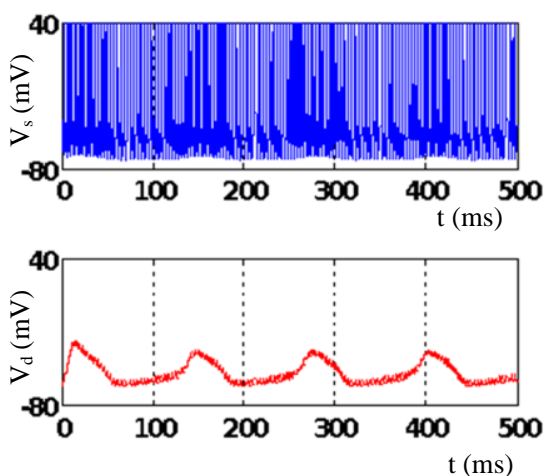

(b)
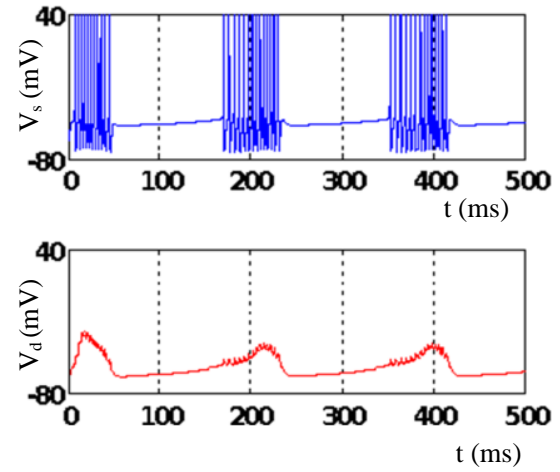

(e)
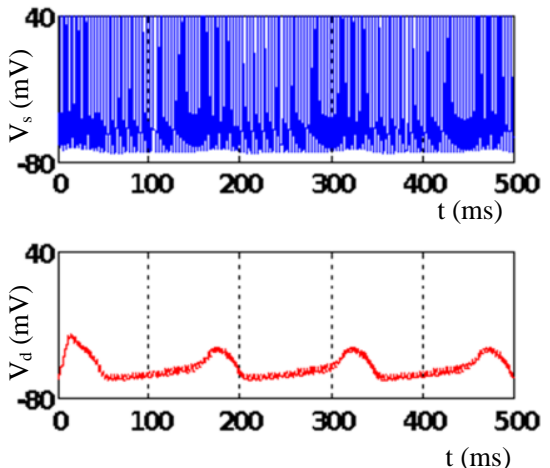

(c)
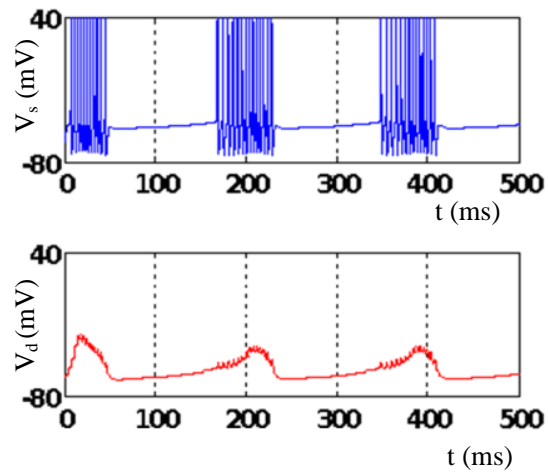

(f)
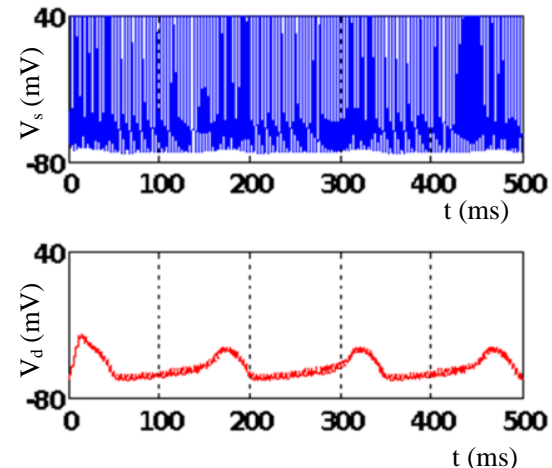

Fig. 14. The time response of the neuron membrane potential of soma $\left(V_{\mathrm{s}}\right)$ and dendrite $\left(V_{\mathrm{d}}\right)$ components in mV. (a), (d) MATLAB simulations of the original simplified P-R model. (b), (e) MATLAB simulations of the proposed piecewise linear model. (c), (f) VIVADO simulation of the designed digital circuit. In these simulations $\left(g_{\mathrm{c}}, p\right)=(0.1,0.15)$ and in (a), (b), (c) $I_{\text {soma }}=7$ and in (d), (e), (f) $I_{\text {soma }}=20$. The first and the third panels show spiking and bursting activities of somatic voltage. The second and the forth panels show spiking and bursting activities of dendrite voltage.

(a)

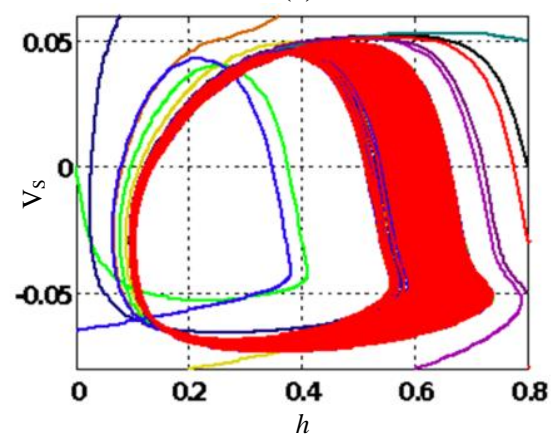

(d)

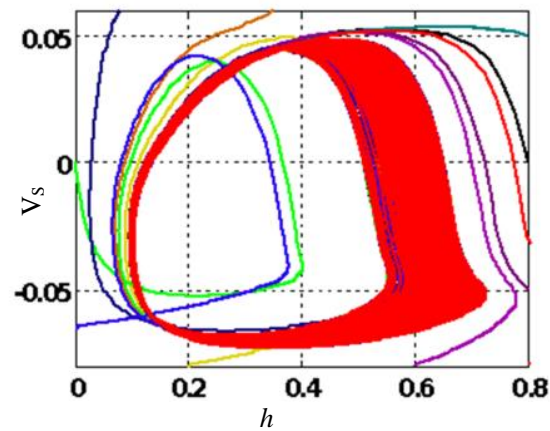

(b)

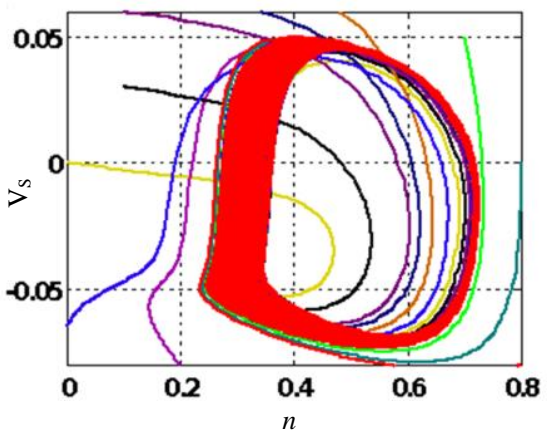

(e)

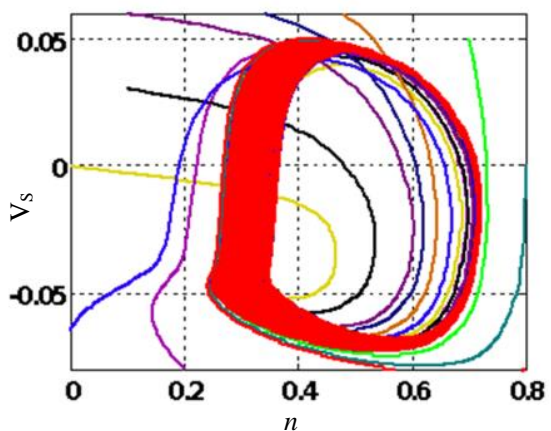

(c)

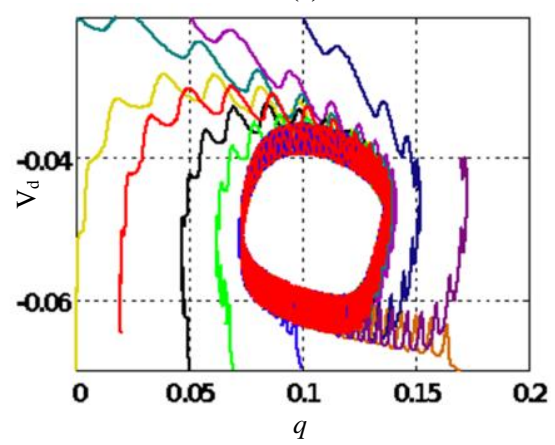

(f)

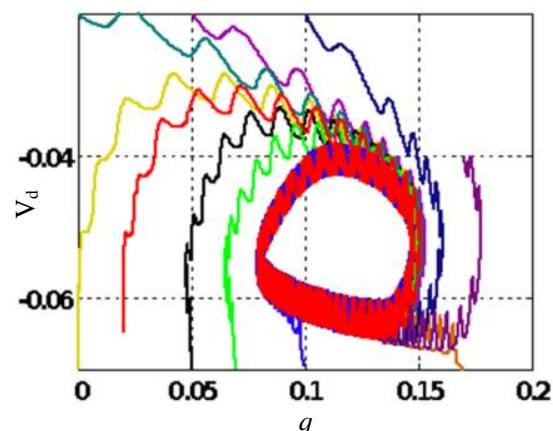

Fig. 15. Phase plane of original and proposed model. (a), (b), (c) show the phase plane of original simplified P-R model. (d), (e), (f) show the phase plane of the proposed digital circuit. The dynamics of network is preserved in the proposed circuit. 
TABLE XIII

THE RMSES AND NRMSEs BETWEEN OBTAINED RESUlTS IN THE ORIGINAL AND PROPOSED MODELS IN MATLAB SiMULATIONS

\begin{tabular}{|c|c|c|c|c|c|c|}
\hline \multirow[b]{2}{*}{$\begin{array}{l}V_{\mathrm{s}} \\
\mathrm{V}_{\mathrm{d}}\end{array}$} & \multicolumn{2}{|c|}{$\left(g_{\mathrm{c}}, p, I_{\text {soma }}\right)=(1,0.15,3)$} & \multicolumn{2}{|c|}{$\left(g_{\mathrm{c}}, p, I_{\text {soma }}\right)=(1,0.15,19.7)$} & \multicolumn{2}{|c|}{$\left(g_{\mathrm{c}}, p, I_{\mathrm{soma}}\right)=(1,0.15,23)$} \\
\hline & $\begin{array}{l}\text { RMSE } \\
0.0138 \\
0.0123\end{array}$ & $\begin{array}{c}\text { NRMSE } \\
0.1333 \\
0.2208\end{array}$ & $\begin{array}{l}\text { RMSE } \\
0.0179 \\
0.0130\end{array}$ & $\begin{array}{c}\text { NRMSE } \\
0.1814 \\
0.2575\end{array}$ & $\begin{array}{l}\text { RMSE } \\
0.0195 \\
0.0104\end{array}$ & $\begin{array}{c}\text { NRMSE } \\
0.1988 \\
0.2075\end{array}$ \\
\hline & \multicolumn{2}{|c|}{$\left(\mathrm{gc}, \mathrm{p}, I_{\mathrm{soma}}\right)=(5,0.15,3)$} & \multicolumn{2}{|c|}{$\left(g_{\mathrm{c}}, p, I_{\text {soma }}\right)=(0.1,0.15,7)$} & \multicolumn{2}{|c|}{$\left(g_{\mathrm{c}}, p, I_{\text {soma }}\right)=(0.1,0.15,20)$} \\
\hline $\begin{array}{l}V_{s} \\
V_{d}\end{array}$ & $\begin{array}{l}\text { RMSE } \\
0.0095 \\
0.0093\end{array}$ & $\begin{array}{c}\text { NRMSE } \\
0.1175 \\
0.1237\end{array}$ & $\begin{array}{l}\text { RMSE } \\
0.0270 \\
0.0091\end{array}$ & $\begin{array}{c}\text { NRMSE } \\
0.2162 \\
0.2344\end{array}$ & $\begin{array}{l}\text { RMSE } \\
0.0428 \\
0.0110\end{array}$ & $\begin{array}{c}\text { NRMSE } \\
0.3515 \\
0.2963\end{array}$ \\
\hline
\end{tabular}

TABLE XIV

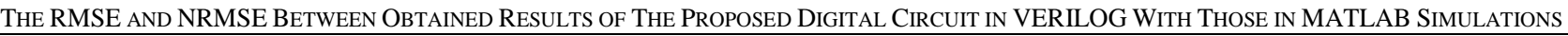

\begin{tabular}{|c|c|c|c|c|c|c|}
\hline & \multicolumn{2}{|c|}{$\left(g_{\mathrm{c}}, p, I_{\mathrm{soma}}\right)=(1,0.15,3)$} & \multicolumn{2}{|c|}{$\left(g_{\mathrm{c}}, p, I_{\text {soma }}\right)=(1,0.15,19.7)$} & \multicolumn{2}{|c|}{$\left(g_{\mathrm{c}}, p, I_{\mathrm{soma}}\right)=(1,0.15,23)$} \\
\hline & RMSE & NRMSE & RMSE & NRMSE & RMSE & NRMSE \\
\hline \multirow{4}{*}{$\begin{array}{l}V_{\mathrm{s}} \\
V_{\mathrm{d}}\end{array}$} & 0.0066 & 0.0633 & 0.0121 & 0.1234 & 0.0171 & 0.1846 \\
\hline & 0.0040 & 0.0715 & 0.0058 & 0.1150 & 0.0081 & 0.1646 \\
\hline & \multicolumn{2}{|c|}{$(\mathrm{gc}, \mathrm{p}$, Isoma $)=(5,0.15,3)$} & \multicolumn{2}{|c|}{$\left(g_{\mathrm{c}}, p, I_{\mathrm{soma}}\right)=(0.1,0.15,7)$} & \multicolumn{2}{|c|}{$\left(g_{\mathrm{c}}, p, I_{\text {soma }}\right)=(0.1,0.15,20)$} \\
\hline & RMSE & NRMSE & RMSE & NRMSE & RMSE & NRMSE \\
\hline $\mathrm{V}_{\mathrm{s}}$ & 0.0060 & 0.0745 & 0.0233 & 0.1873 & 0.0318 & 0.2607 \\
\hline $\mathrm{V}_{\mathrm{d}}$ & 0.0058 & 0.0764 & 0.0027 & 0.0719 & 0.0018 & 0.0478 \\
\hline
\end{tabular}

In Fig. 12, the first and the third panels show the bursting activities of somatic compartment (blue color) and the second and the fourth panels display the bursting activities of dendrite compartment (red color). Fig. 12(a), (d) illustrates the MATLAB simulations of the membrane potential of original simplified P-R model, and (b), (e) are the MATLAB simulations of the proposed piece-wise linear model, and (c), (f) are the VIVADO simulation of the designed digital circuit. Comparing different panels, it is evident that both piecewise linear model and digital circuit produce similar responses to original biophysical P-R model. Additionally, by increasing the injection current to soma (i.e., $I_{\text {soma }}=19.7$ ), the firing frequency is also increased and tonic bursting activities can be appeared in digital circuit.

Next, we examine the spiking activities in the digital circuit of the 2-compartmnetal model. Fig. 13 shows the spiking activities of the simplified P-R neuron model. For simulation illustrated in Fig. 13, $p=0.15$ and for (a) $g_{\mathrm{c}}=1, I_{\text {soma }}=23$, for (b), (c) $g_{\mathrm{c}}=1, I_{\text {soma }}=34$, for (d), (e), (f) $g_{\mathrm{c}}=5, I_{\text {soma }}=3$. In Fig. 13, the first and the third panels show the bursting/spiking behavior of somatic compartment (blue color) and the second and the forth panels display the bursting/spiking activities of dendrite compartment (red color). As can be seen, the results of MATLAB simulation of the membrane potential of original simplified P-R model which is shown in Fig.13 (a), (d) not only have good agreement with the MATLAB simulations of the proposed piecewise linear model illustrated in (b), (e) but also with the VIVADO simulation of the digital circuit shown in (c), (f).

In the third set of simulations, we investigate the effect of variation of $g_{\mathrm{c}}$, which couple the somatic and dendritic components. When somatic and dendritic compartments are strongly coupled (e.g. $g_{\mathrm{c}}=5$ ), the spikes will be generate as shown in Fig. 13 (d), (e), (f). On the other hand, when $g_{\mathrm{c}}$ is weak (e.g. $g_{\mathrm{c}}=0.1$ ), the burst entirely change and the dendritic component cannot follow somatic part, showing a small hump during a burst, as shown in the second panel of Fig. 14 (a), (b), (c). In Fig. 14 (d), (e), (f), a larger current is injected to the soma, thus the bursting patterns disappears and spiking activities are modulated in frequency.

The phase plane, $\left(V_{\mathrm{s}}-h\right),\left(V_{\mathrm{s}}-n\right),\left(V_{\mathrm{d}-}-q\right)$, of the simplified P-R neuron model (a) ,(b), (c) and for the proposed digital circuit (d), (e), (f) are shown in Fig. 15. As can be observed, although there are also some quantitative differences, the general shape and the qualitative behavior of trajectories are similar. Regarding the obtained results, one can conclude that the dynamical characteristics of the original system are preserved by the designed circuit.

Computing RMSE and NRMSE, the reliability of the proposed model is supported. Table XIII shows the RMSE and NRMSE between biophysical P-R and proposed piecewise linear models in MATLAB, and Table XIV presents the RMSE and NRMSE between simulations of digital circuit in VIVADO with the original model in MATLAB.

Considering Fig. 12, 13, 14, and 15, the digital circuit maintains the essential properties of its biological counterpart in different conditions. Considering the important criteria from the hardware point of view such as scaling up the designed circuit, reducing the digital implementation cost and keeping low power operation while obtaining results similar to the biophysical model of P-R model, the proposed circuit produces acceptable results. 


\section{Conclusion}

Design and effective implementation of spiking neural network in hardware is now an active domain of research and several procedures have been proposed for designing and construction of brain like processing systems for conventional computing. The focus of this paper was to propose a piecewise linear model and a digital circuit for the simplified PinskyRinzel neuron model to verify that both proposed linearized and digital circuit can produce similar responses as the biophysical model does. This work can be considered as a basic step towards creating adaptable and bio-plausible hardwarebased neural network using simplified Pinsky-Rinzel neuron model. The results of the FPGA implementation are in agreement with those Matlab and Vivado simulations. Future works aim at extending this model and creating a neural population model and constructs a spiking neural network in digital domain. These issues will be addressed in future study.

\section{REFERENCES}

[1] M. Amiri, E. Davoodi-Bojd, F. Bahrami, and M. Raza, "Bifurcation analysis of the Poincaré map function of intracranial EEG signals in temporal lobe epilepsy patients," IMAC Trans. Math. Compute. , vol. 81, no. 11, pp. 2471-2491, Jul. 2011.

[2] E. Bullmore and O. Sporns, "Complex brain networks: graph theoretical analysis of structural and functional systems." Nat. Rev. Neuro., vol. 10, no. 3, pp. 186-198, Mar. 2009.

[3] M. Amiri, F. Bahrami, and M. Janahmadi, "On the role of astrocytes in epilepsy: a functional modeling approach." J. Neuro. research, vol. 72, no. 2, pp. 172-180, Feb. 2012.

[4] E. M. Izhikevich, "Simple model of spiking neurons." IEEE Trans. Neuro. Netw., vol. 14, no. 6, pp. 1569-1572, Nov. 2003.

[5] M. R. Azghadi, S. Al-Sarawi, D. Abbott, and N. Iannella, "A neuromorphic VLSI design for spike timing and rate based synaptic plasticity." Neural Netw. vol. 45, pp. 70-82, Sep. 2013.

[6] A. L. Hodgkin, A. F. Huxley, "A quantitative description of membrane current and its application to conduction and excitation in nerve." $J$. Physiol., vol. 117, no.4, pp. 500-544, Aug. 1952.

[7] S. B. Furber, S. Temple, and A. D. Brown, "High-performance computing for systems of spiking neurons." AISB'06 workshop Architect. Bra. Mind, vol. 2, pp. 29-36, Apr. 2006.

[8] S. Nazari, K. Faez, M. Amiri, and E. Karami "A digital implementation of neuron-astrocyte interaction for neuromorphic applications." Neural Netw. vol. 66, pp. 79-90, Jun. 2015.

[9] J. J. Wade, L. J. McDaid, J. Harkin, V. Crunelli, J. S. Kelso, and V. Beiu, "Exploring retrograde signaling via astrocytes as a mechanism for self repair," in Proc. IJCNN, 2011, pp. 3149-3155.

[10] J. Wade, L. McDaid, J. Harkin, V. Crunelli, and S. Kelso. (2012, Sep.). Self-repair in a bidirectionally coupled astrocyte-neuron (AN) system based on retrograde signaling. Front. Comput. Neurosci. [Online]. 6(76), pp. $1-12$. Available: http://journal.frontiersin.org/article/10.3389/fncom.2012.00076/full

[11] M. Naeem, L. J. McDaid, J. Harkin, J. J. Wade, and J. Marsland, "On the role of astroglial syncytia in self-repairing spiking neural networks," IEEE Trans. Neural Netw., vol. 26, no. 10, pp. 2370-2380, Oct. 2015.

[12] J. Liu, J. Harkin, L. Maguire, L. McDaid, J. Wade, and M. McElholm, "Self-repairing hardware with astrocyte-neuron networks," in Proc. ISCAS, 2016, pp. 1350-1353.

[13] J. Liu, J. Harkin, L. McDaid, D. M. Halliday, A. M. Tyrrell, and J. Timmis, "Self-repairing mobile robotic car using astrocyte-neuron networks," in Proc. IJCNN, 2016, pp. 1379-1386.

[14] A. P. Johnson, D. M. Halliday, A. G. Millard, A. M. Tyrrell, J. Timmis, J. Liu, J. Harkin, L. McDaid, and S. Karim,“ An FPGA-based hardwareefficient fault-tolerant astrocyte-neuron network," in Proc. SSCI, 2016, pp. 1-8.

[15] M. Amiri, F. Bahrami, and M. Janahmadi, "Functional contributions of astrocytes in synchronization of a neuronal network model." J. Theo. Bio. , pp. 60-70, Jan. 2012.
[16] M. Amiri, N. Hosseinmardi, F. Bahrami, and M. Janahmadi, "Astrocyteneuron interaction as a mechanism responsible for generation of neural synchrony: a study based on modeling and experiments." J. Comput. Neurosci. , vol. 34, no. 3, pp. 489-504, Jun. 2013.

[17] M. Amiri, G. Montaseri, and F. Bahrami, "On the role of astrocytes in synchronization of two coupled neurons: a mathematical perspective." $J$. Bio. Cybemetics, vol. 105, no. 2, pp. 153-166, Aug. 2011.

[18] E. T. Rolls, and R. P. Kesner, "A computational theory of hippocampal function, and empirical tests of the theory." J. Pro. Neurobio. , vol. 79, no. 1, pp. 1-48, May. 2006.

[19] L. A. Atherton, L. Y. Prince, and K. Tsaneva-Atanasova, "Bifurcation analysis of a two-compartment hippocampal pyramidal cell model." $J$. Comput. Neurosci. , vol. 41, no. 1, pp. 91-106, Aug. 2016.

[20] R. D. Traub, R. K. Wong, R. Miles, and H. Michelson, "A model of a CA3 hippocampal pyramidal neuron incorporating voltage-clamp data on intrinsic conductances." J. Neurophy. , vol. 66, no. 2, pp. 635-650, Aug. 1991.

[21] P. F. Pinsky, and J. Rinzel, "Intrinsic and network rhythmogenesis in a reduced Traub model for CA3 neurons." J. Comput. Neurosci., vol. 1, no. 1-2, pp. 39-60, Jun. 1994.

[22] A. Kepecs, and X. J. Wang, "Analysis of complex bursting in cortical pyramidal neuron models." J. Neurocom. , vol. 32, pp. 181-187, Jun. 2000.

[23] A. Kepecs, and X. J. Wang, and J. Lisman, "Bursting neurons signal input slope." J. Neurosci. , vol. 22, no. 20, pp. 9053-9062, Oct. 2002

[24] M. Amiri, G. Montaseri, and F. Bahrami, "A phase plane analysis of neuron-astrocyte interactions." Neural Netw. vol. 44, pp. 157-165, Aug. 2013.

[25] M. Amiri, M. Amiri, S. Nazari, and K. Faez, "A new bio-inspired stimulator to suppress hyper-synchronized neural firing in a cortical network." J. Theo. Bio. , vol. 410, pp. 107-118, Dec. 2016.

[26] M. R. Azghadi, B. Linares-Barranco, D. Abbott, and P. H. Leong, "A Hybrid CMOS-Memristor Neuromorphic Synapse.” IEEE Trans. Biomed. Circuits Syst. , pp. 1-12, Dec. 2016.

[27] T. Hishiki, and H. Torikai, "A novel rotate-and-fire digital spiking neuron and its neuron-like bifurcations and responses," IEEE Trans. Neural Netw., vol. 22, no. 5, pp. 752-767, May. 2011.

[28] T. Nanami, and T. Kohno. (2016, May.). Simple cortical and thalamic neuron models for digital arithmetic circuit implementation. Front. Neurosci. [Online]. 10(181), pp. 1-12. Available: https://www.ncbi.nlm.nih.gov/pmc/articles/PMC4865656/

[29] S. Nazari, M. Amiri, K. Faez, and M. Amiri, "Multiplier-less digital implementation of neuron-astrocyte signalling on FPGA." J. Neurocom. , vol. 164, pp. 281-292, Sep. 2015.

[30] S. Saïghi, C. G. Mayr, T. Serrano-Gotarredona, H. Schmidt, G. Lecerf, J. Tomas, J. Grollier, S. Boyn, A. F. Vincent, D. Querlioz, and S. La Barbera. (2015, Mar.). Plasticity in memristive devices for spiking neural networks. Front. Neurosci. [Online]. 9(51), pp. 1-16. Available: http://journal.frontiersin.org/article/10.3389/fnins.2015.00051/full

[31] T. Serrano-Gotarredona, T. Masquelier, T. Prodromakis, G. Indiveri, and B. Linares-Barranco. (2013, Feb.). STDP and STDP variations with memristors for spiking neuromorphic learning systems. Front. Neurosci. [Online]. $\quad 7(2), \quad$ pp. 1-15. Available: http://journal.frontiersin.org/article/10.3389/fnins.2013.00002/full

[32] A. Yousefzadeh, L. A. Plana, S. Temple, T. Serrano-Gotarredona, S. B. Furber, and B. Linares-Barranco, "Fast Predictive Handshaking in Synchronous FPGAs for Fully Asynchronous Multisymbol Chip Links: Application to SpiNNaker 2-of-7 Links." IEEE Trans. Circuits Syst. , vol. 63, n. 8, pp. 763-767, Aug. 2016.

[33] J. H. Wijekoon, and P. Dudek, "VLSI circuits implementing computational models of neocortical circuits." J. Neurosci. Methods, vol. 210, no. 1, pp. 93-109, Sep. 2012.

[34] V. Kakkar, "Comparative study on analog and digital neural networks." Int. J. Comput. Sci. Netw. Secur., vol. 9, no. 7, pp. 14-21, Jul. 2009.

[35] J. W. Cho, and S. Y. Lee, "Active noise canceling using analog neurochip with on-chip learning capability," in Proc. Adv. Neural Inf. Proc. Syst., 1999, pp. 664-670.

[36] W. X. Li, R. C. Cheung, R. H. Chan, D. Song, T. W. and Berger, "Realtime prediction of neuronal population spiking activity using FPGA." IEEE Trans. Biomed. Circuits Syst., vol. 7, no. 4, pp. 489-498, Aug. 2013.

[37] K. L. Rice, M. A. Bhuiyan, T. M. Taha, C. N. Vutsinas, and M. C. Smith, "FPGA implementation of Izhikevich spiking neural networks for character recognition," in Proc. Int. Conf. IEEE, 2009, pp. 451-456. 
[38] A. Ghani, C. H. See, and S. M. U. Ali, "Step forward to map fully parallel energy efficient cortical columns on field programmable gate arrays." IET Sci. Measure. Tech., vol. 8, no. 6, pp. 432-440, Sep. 2014. 